\title{
Hypoxia and sterile inflammation in cystic fibrosis airways: mechanisms and potential therapies
}

\author{
Samuel T. Montgomery ${ }^{1}$, Marcus A. Mall ${ }^{2,3,9}$, Anthony Kicic ${ }^{1,4,5,6,9}$ and \\ Stephen M. Stick ${ }^{1,4,5,6,9}$ on behalf of AREST CF $1,5,7,8$
}

\begin{abstract}
Affiliations: 'School of Paediatrics and Child Health, The University of Western Australia, Nedlands, Australia. ${ }^{2}$ Dept of Translational Pulmonology, Translational Lung Research Center Heidelberg (TLRC), Member of the German Center for Lung Research (DZL), University of Heidelberg, Heidelberg, Germany. ${ }^{3}$ Division of Pediatric Pulmonology and Allergy, Cystic Fibrosis Center, Dept of Pediatrics, University of Heidelberg, Heidelberg, Germany. ${ }^{4}$ Telethon Kids Institute, Centre for Health Research, The University of Western Australia, Nedlands, Australia. ${ }^{5}$ Dept of Respiratory Medicine, Princess Margaret Hospital for Children, Perth, Australia. ${ }^{6}$ Centre for Cell Therapy and Regenerative Medicine, School of Medicine and Pharmacology, The University of Western Australia, Nedlands, Australia. ${ }^{7}$ Murdoch Children's Research Institute, Parkville, Melbourne, Australia. ${ }^{8}$ Dept of Paediatrics, University of Melbourne, Parkville, Melbourne, Australia. ${ }^{9}$ These authors contributed equally.
\end{abstract}

Correspondence: Anthony Kicic, Telethon Kids Institute, Subiaco, Perth, 6008, Western Australia, Australia. E-mail: Anthony.Kiciclatelethonkids.org.au

@ERSpublications

Hypoxia and sterile inflammation is characteristic in cystic fibrosis airways leading to lung damage in early life http://ow.ly/NnHf304acAZ

Cite this article as: Montgomery ST, Mall MA, Kicic A, et al. Hypoxia and sterile inflammation in cystic fibrosis airways: mechanisms and potential therapies. Eur Respir J 2017; 49: 1600903 [https://doi.org/ 10.1183/13993003.00903-2016].

ABSTRACT Cystic fibrosis is one of the most common autosomal recessive genetic diseases in Caucasian populations. Diagnosis via newborn screening and targeted nutritional and antibiotic therapy have improved outcomes, however respiratory failure remains the key cause of morbidity and mortality. Progressive respiratory disease in cystic fibrosis is characterised by chronic neutrophilic airway inflammation associated with structural airway damage leading to bronchiectasis and decreased lung function. Mucus obstruction is a characteristic early abnormality in the cystic fibrosis airway, associated with neutrophilic inflammation often in the absence of detectable infection. Recent studies have suggested a link between hypoxic cell death and sterile neutrophilic inflammation in cystic fibrosis and other diseases via the IL-1 signalling pathway. In this review, we consider recent evidence regarding the cellular responses to respiratory hypoxia as a potential driver of sterile neutrophilic inflammation in the lung, current knowledge on hypoxia as a pathogenic mechanism in cystic fibrosis and the potential for current and future therapies to alleviate hypoxia-driven sterile inflammation.

Received: May 052016 | Accepted after revision: Aug 312016

Support statement: US Cystic Fibrosis Foundation, Cystic Fibrosis Australia and the German Federal Ministry of Education and Research (82DZL004A1) provided funding.

Conflict of interest: Disclosures can be found alongside this article at erj.ersjournals.com 


\section{Introduction}

Cystic fibrosis is one of the most common autosomal recessive genetic disease in Caucasian populations of European descent $[1,2]$, with an incidence of 1 in 3630 live births in Australia [3]. Diagnosis via newborn screening and targeted nutritional and antibiotic therapy has improved outcomes so that the median long-term survival is now into middle adulthood [4-6]. However, respiratory failure remains the key cause of morbidity and mortality and current preventative therapies targeting airways disease have limited efficacy $[4,5,7]$. Cystic fibrosis results from mutations in the cystic fibrosis transmembrane regulator $(C F T R)$ gene; mutations in CFTR result in the absence or reduction of functional CFTR anion channels in the apical membrane of airway epithelial cells, affecting secretion of chloride $\left(\mathrm{Cl}^{-}\right)$, bicarbonate $\left(\mathrm{HCO}_{3}^{-}\right)$ and other anions [8]. Reduced epithelial $\mathrm{Cl}^{-}$transport [9] combined with excessive epithelial sodium $\left(\mathrm{Na}^{+}\right)$transport via the epithelial $\mathrm{Na}^{+}$channel (ENaC) [10-14] results in dehydration of the airway surface liquid and impaired mucociliary clearance [15]. Depletion of airway surface liquid increases the concentration and viscosity of the mucus layer, which is exacerbated by hypersecretion of mucins in chronic airway inflammation [16] and leads to the formation of thickened mucus plaques on airway surfaces and plugging of the airway lumen [17]. Increased epithelial oxygen consumption associated with increased ENaC-mediated $\mathrm{Na}^{+}$absorption [18] combined with luminal hypoxia due to mucus plugging creates steep oxygen gradients within adherent mucus, unique to the cystic fibrosis airway [17]. The hypoxic niches within thickened mucus provide a nidus for motile bacteria able to penetrate the mucus encouraging anaerobic bacterial growth and colonisation [17].

Progressive respiratory disease in cystic fibrosis is characterised by chronic neutrophilic airway inflammation, typified by increased membrane-bound and free neutrophil elastase activity [19, 20]. Neutrophilic airway inflammation is associated with structural airway remodelling, bronchiectasis and decreased lung function [20-23]. Mucus obstruction is a characteristic early abnormality in the cystic fibrosis airway [23], associated with neutrophilic inflammation [24] often in the absence of detectable infection $[20,22]$, leading to the question of what drives early sterile inflammation in cystic fibrosis. Recent studies have suggested a link between hypoxic cell death and sterile neutrophilic inflammation in cystic fibrosis and other diseases via the IL-1 signalling pathway [25-29]. In this review, we consider recent evidence regarding the cellular responses to respiratory hypoxia as a driver of sterile neutrophilic inflammation in the lung, current knowledge on hypoxia as a pathogenic mechanism in cystic fibrosis and the potential for current and future therapies to alleviate hypoxia-driven sterile inflammation.

\section{Physiological and transcriptional responses to respiratory hypoxia}

Respiratory hypoxia is uniquely characteristic of the cystic fibrosis airway; although, young children with cystic fibrosis are typically normoxic. Two respiratory issues evident in children with cystic fibrosis are regional hypoxia in the airway lumen due to obstructive mucus plugging $[20,22,23]$ and increased epithelial oxygen consumption most likely due to elevated $\mathrm{Na}^{+} / \mathrm{K}^{+}$ATPase activity involved in increased ENaC-mediated $\mathrm{Na}^{+}$absorption $[10,11,15,18]$. Both abnormalities may result in airway epithelial cells vulnerable to cellular hypoxia and ensuing necrosis [27]. Hypoxaemia is also present in patients with chronic or advanced lung disease [30]. Increased oxygen consumption creates steep oxygen gradients within thickened mucus in airway surface liquid and hypoxic niches primed for anaerobic growth of Pseudomonas aeruginosa, driving antibiotic resistance in biofilms observed in cystic fibrosis [17, 31]. However, significant inflammation in the absence of respiratory infection is present at diagnosis in a majority of infants with cystic fibrosis, and significant gas trapping is observed [20,32].

\section{Physiological responses to respiratory hypoxia}

Alveolar oxygen pressure during normoxia is unusually high [33-35], and thus respiratory hypoxia occurs at a higher oxygen tension compared with other organs. Even moderate levels of alveolar hypoxia experienced at high altitudes are sufficient to trigger an inflammatory phenotype. Elevated presence of macrophages, neutrophils and inflammatory cytokines have been observed in bronchoalveolar lavage fluid (BALF) isolated from humans exposed to hypobaric hypoxia [36]. With significant gas trapping [20, 32] and episodes of nocturnal oxygen desaturation [37] observable in infants with cystic fibrosis, the physiological response to hypoxia may play a role in early lung damage in cystic fibrosis. The physiological response of the pulmonary vascular system to hypoxia is hypoxic pulmonary vasoconstriction, resulting from hypoxia-induced $\mathrm{K}^{+}$current inhibition and membrane depolarisation in pulmonary arterial smooth muscle cells $[38,39]$. Significant abnormal pulmonary perfusion has been observed in infants and young children with cystic fibrosis suggesting perfusion deficits are associated with airway disease, even when clinically stable [23]. Chronic pulmonary vasoconstriction can lead to pulmonary hypertension, and vascular remodelling caused by chronic hypoxia and hypertension may contribute to structural remodelling observed in early cystic fibrosis lung damage [32, 40]. 
Transcriptional responses to respiratory hypoxia

The transcriptional response to hypoxia has also been extensively studied in vivo and in vitro, elucidating important factors involved (figure 1). Hypoxia-inducible factor (HIF)-1 plays a vital role in the response to hypoxia, inducing the transcription of proteins to increase oxygen availability. The HIF-1 complex exists as a heterodimer, consisting of subunits HIF- $1 \alpha$ and HIF-1 [41]. HIF-1 $\beta$ is constitutively expressed, whereas HIF- $1 \alpha$ expression is facultative and regulated in an oxygen-dependent manner. During normoxia, HIF- $1 \alpha$ is hydroxylated by prolyl hydroxylase domain (PHD) proteins using oxygen as a substrate, leading to interactions with the von Hippel-Lindau (VHL) E3 ligase complex, subsequent ubiquitination, and proteosomal degradation of HIF-1 $\alpha$ [42-44]. As the degradation of HIF-1 $\alpha$ requires oxygen for PHD activity and ubiquitination via VHL, hypoxic conditions result in the stabilisation and translocation of HIF- $1 \alpha$ [43]. In cystic fibrosis, lack of CFTR function affects HIF- $1 \alpha$ stabilisation, with in vitro experiments finding lower expression of HIF- $1 \alpha$ in cystic fibrosis airway epithelial cells during hypoxia when compared to healthy controls [45]. This is possibly due to impaired control of intracellular reactive oxygen species (ROS) [46] resulting from loss of CFTR transport of the antioxidant glutathione $[47,48]$, affecting the adaptive response to hypoxia in cystic fibrosis [49].

\section{$N F-\kappa B$ transcription during hypoxia}

Even though HIF- $1 \alpha$ is the predominant transcription factor activated during hypoxia, activation of NF- $\kappa \mathrm{B}$ is another critical and largely HIF-1 $\alpha$-independent transcriptional response [50]. During hypoxia, activation of $\mathrm{NF}-\kappa \mathrm{B}$ is rapid, persistent and $\mathrm{I} \kappa \mathrm{B}$ kinase (IKK) dependent, instigated by the phosphorylation of nuclear factor of kappa light polypeptide gene enhancer in B-cells inhibitor- alpha $(\mathrm{I} \kappa \mathrm{B} \alpha)[50,51]$. Inhibition of PHDs during hypoxia increases IKK- $\beta$ catalytic activity [52], resulting in greater $\mathrm{I} \kappa \mathrm{B} \alpha$ phosphorylation and $\mathrm{NF}-\kappa \mathrm{B}$ activation $[51,53]$. The initial activation of $\mathrm{NF}-\kappa \mathrm{B}$ is too rapid

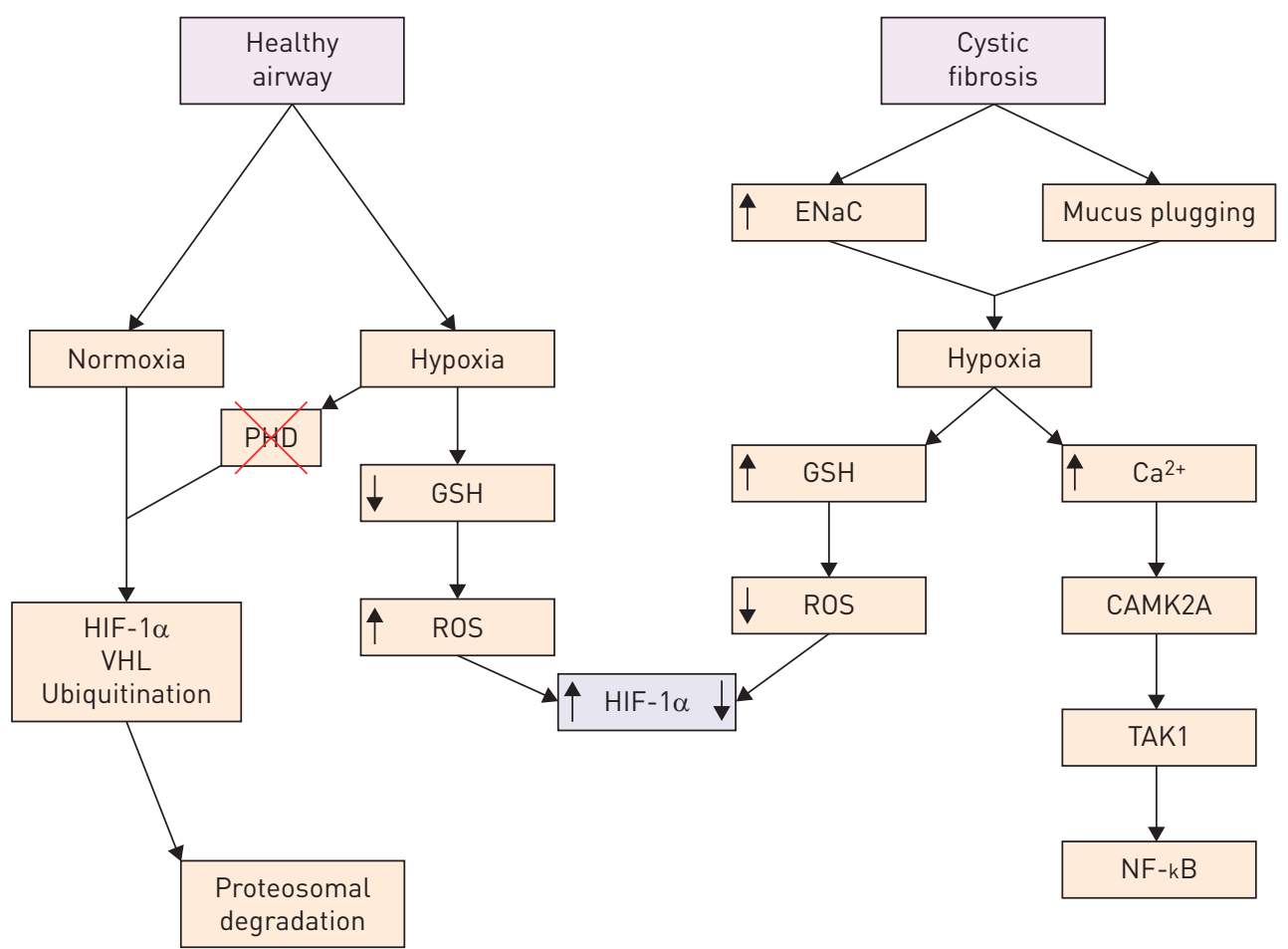

FIGURE 1 Transcriptional response to hypoxia in normal and cystic fibrosis airways. Hypoxia-inducible factor (HIF)- $1 \alpha$ plays a central role in the transcriptional response to hypoxia. In normal airways, under normoxic conditions HIF- $1 \alpha$ is hydroxylated by prolyl hydroxylase domains (PHDs) and through subsequent interactions with the von Hippel-Lindau (VHL) E3 complex, marked for ubiquitination and proteosomal degradation. Under hypoxic conditions, PHD activity is inhibited and HIF-1 $\alpha$ is stabilised. Hypoxia also results in the efflux of intracellular glutathione (GSH) via cystic fibrosis transmembrane conductance regulator (CFTR), causing intracellular reactive oxygen species (ROS) to accumulate, contributing to increased HIF- $1 \alpha$ stabilisation. In cystic fibrosis airways, impaired ventilation due to airway mucus obstruction and increased epithelial sodium channel (ENaC) activity result in cellular hypoxia of airway epithelial cells. Hypoxia causes Ca ${ }^{2+}$ influx and calcium/calmodulin-dependent protein kinase type II (CAMK2) activation, transforming-growth-factor$\beta$-activated protein kinase 1 (TAK1) activation and subsequent nuclear factor $\kappa \mathrm{B}$ (NF- $\kappa \mathrm{B})$ activation. In the absence of functioning CFTR, there is increased intracellular GSH and lower ROS generation, resulting in reduced stabilisation of $\mathrm{HIF}-1 \alpha$. 
for a transcriptional response to hypoxia; instead $\mathrm{Ca}^{2+}$ dependent activation of $\mathrm{Ca}^{2+} / \mathrm{calmodulin}^{-}$ dependent protein kinase II (CAMK2) occurs prior to the inhibition of PHDs [54]. This demonstrates

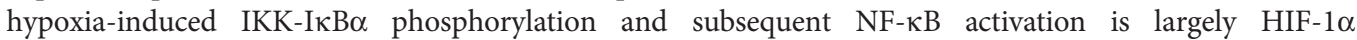
independent [50], with basal activation of NF- $\mathrm{B}$ required for HIF-1 $\alpha$ accumulation under hypoxia [55]. However, activation of NF- $\mathrm{BB}$ during hypoxia is reduced in cells lacking functional CFTR, suggesting an impaired response in cystic fibrosis [56]. These data highlight the multifaceted transcriptional and physiological response to respiratory hypoxia, and the interconnectivity between classic hypoxia-response genes and the NF- $\kappa \mathrm{B}$ inflammatory pathway. Furthermore, these mechanisms may be relevant in cystic fibrosis lung disease, with reduced NF- $\kappa B$ activation [56] and lower HIF-1 $\alpha$ stabilisation in cells lacking functional CFTR, contributing to an impaired response to hypoxia in cystic fibrosis.

\section{Hypoxia and inflammation in cystic fibrosis}

Chronic neutrophilic airway inflammation is a key factor in driving mortality and morbidity present in cystic fibrosis. Neutrophil elastase, the primary product of activated neutrophils, is important in host defence against bacteria such as Pseudomonas aeruginosa [57], but elevated neutrophil elastase can also result in cleaving of chemokine receptors on immune cells, compromising their capacity to kill bacteria [58]. Elevated neutrophil elastase also exacerbates ion transport imbalance in cystic fibrosis, activating near-silent ENaC transport and degrading CFTR channels and disabling ion transport [59, 60]. Detection of free neutrophil elastase in BALF is the most significant predictor for presence of bronchiectasis in early cystic fibrosis [22] and neutrophil elastase was linked to structural lung damage in mice with cystic fibrosis-like lung disease [19]. Airway infection is a predominant and persistent cause of neutrophilic inflammation in cystic fibrosis [61]. However, inflammation can be seen in asymptomatic children with cystic fibrosis without lower airway colonisation [32], and the pathogenesis of non-infectious inflammation in these cases is poorly understood. Recent studies in $\beta \mathrm{ENaC}$-overexpressing mice with cystic fibrosis-like lung disease $[11,62]$ led to novel insights how mucus obstruction may be linked to neutrophilic inflammation in early cystic fibrosis lung disease. First, a study utilising this model of cystic fibrosis lung disease derived in germ-free conditions observed airway mucus obstruction and persistent inflammation in the absence of bacteria, with significantly higher neutrophil presence in BALF compared with germ-free wildtype mice [63]. These results suggest that mucus plugging per se can trigger chronic airway inflammation even in the absence of bacterial infection. Early neutrophilic inflammation is important in the pathogenesis of cystic fibrosis, with neutrophils and airway mucus plugging present in infants at diagnosis $[20,32]$. Second, studies in $\beta E N a C$-overexpressing mice with cystic fibrosis-like lung disease demonstrate that airway mucus plugging is associated with cellular hypoxia resulting in necrosis of airway epithelial cells [24]. Additionally, a recent study demonstrated that necrosis of airway epithelial cells is a characteristic finding in cystic fibrosis patients and that necrotic airway cells are correlated with the severity of mucus plugging in small airway lung sections [27]. These results suggest that elucidating the link between hypoxia-driven epithelial necrosis and early neutrophilic inflammation may be vital in attenuating cystic fibrosis-associated morbidity and mortality.

\section{Sterile inflammation}

Unlike inflammation resulting from infection, driven by the toll-like receptor network, sterile inflammation during hypoxia is mediated via the activation of interleukin-1 receptor (IL-1R) (figure 2) $[25,27]$. Activation of IL-1R occurs when hypoxic cells undergoing necrosis release IL- $1 \alpha$, which acts as a danger-associated molecular pattern molecule $[25,27]$. The inflammatory role of IL-1 has been thoroughly investigated in a number of inflammatory [64] and hypoxic diseases such as ischaemia, where it influences inflammation in the cerebrum [29], as well as renal [65] and cardiac systems [66, 67]. CHEN et al. [25] determined that IL- $1 \alpha$, not IL-1 $\beta$ was responsible for the inflammatory response to cell death using in vivo knockout murine models. A recent study by FrITZSCHING et al. [27] also demonstrated that epithelial necrosis in the airways of $\beta E N a C$-overexpressing mice is associated with an increase in neutrophils in BALF, as well as elevated IL- $1 \alpha$ levels. Interestingly, genetic deletion and pharmacological inhibition of IL-1R resulted in significantly reduced airway neutrophilia airway mucus obstruction and structural lung damage, but had no effect on airway epithelial necrosis or IL-1 $\alpha$ in BALF [27].

Necrotic airway cells trigger a sterile inflammatory response by the passive release of IL-1 $\alpha$, which is trafficked to the nucleus and contained during apoptosis [68]. However during necrosis, IL-1 $\alpha$ is released from cells in biologically active uncleaved and cleaved forms [25, 69]. Furthermore, extracellular IL-1 $\alpha$ released from primary airway epithelial cells exposed to oxidative stress is able to trigger an inflammatory phenotype in lung fibroblasts [70], reiterating the inflammatory capacity of IL-1 $\alpha$ during necrosis. IL- $1 \alpha$ exists natively as a precursor protein that is cleaved via calpain [71], but cleavage can be inhibited by binding of IL-1 $\alpha$ to IL-1R2 [72]. Intriguingly, IL-1R2 expression is reported to be absent in both immortalised airway epithelial cell lines and primary airway epithelial cells, which suggests airway 


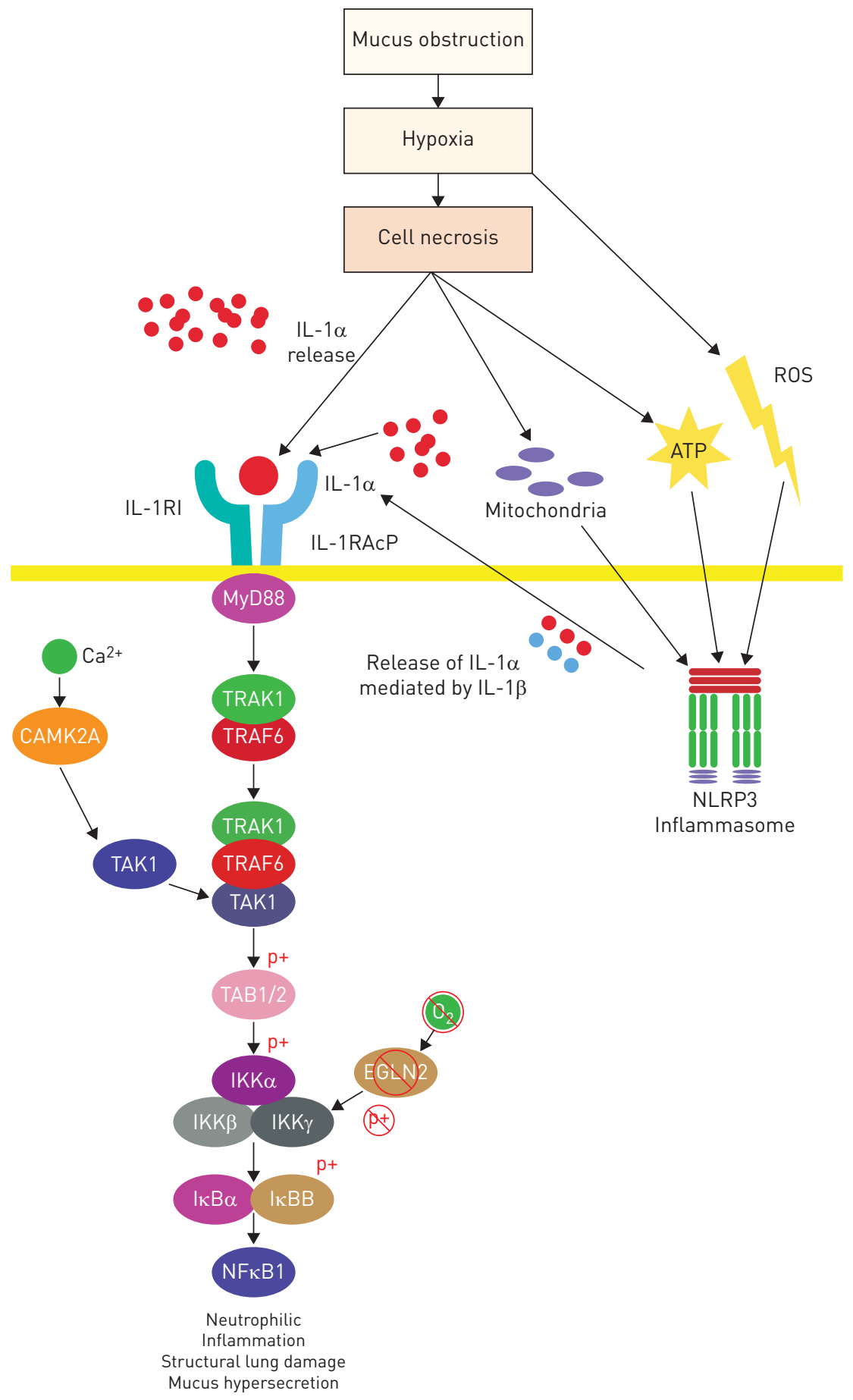

FIGURE 2 Transcriptional inflammatory response to hypoxia and cellular necrosis. Cellular hypoxia results in the release of IL-1 $\alpha$ through two mechanisms - hypoxic necrosis of epithelial cells passively releasing IL-1 $\alpha$, or through Nod-like receptor protein 3 (NLRP3) inflammasome activation via reactive oxygen species (ROS) generation and cell products released from cells undergoing necrosis. Binding of IL-1 $\alpha$ to IL-1R recruits MyD88 to the IL-1R:IL-1RAcP complex, and results in activation of transforming-growth-factor- $\beta$-activated protein kinase 1 (TAK1) by interacting with IL-1 receptor-activated protein kinase (IRAK1):tumour necrosis factor receptor-associated factor 6 (TRAF6). TAB1 phosphorylates IKB kinase (IKK) $\gamma$, which binds to IKK $\alpha$ and IKK $\beta$ activating the IKK complex. The IKK complex phosphorylates nuclear factor $\kappa B(N F-\kappa B)$ inhibitors $1 \kappa B \alpha$ and $\mid \kappa B \beta$, subsequently activating NF- $\kappa B 1$. Initial activation of NF- $\kappa B$ during hypoxia is mediated by intracellular $\mathrm{Ca}^{2+}$ activating calcium/calmodulin-dependent protein kinase type IIA (CAMK2A), which activates TAK1 and the subsequent pathway prior to IL-1 $\alpha$ release. Hypoxia also inhibits egl-9 family hypoxia-inducible factor 2 (EGLN2) degrading IKK $\beta$, increasing catalytic activity and greater NF-KB activation. 
epithelial cells lack the ability to regulate IL-1 $\alpha$ activity due to an inability to express IL-1R2 [73], which may contribute to the hyper-inflammatory response observed in cystic fibrosis.

\section{IL-1 $\alpha$ role and regulation}

Aside from the release from necrotic cells, there is a paucity of data about the regulation and physiological role of IL-1 $\alpha$. Previously, it was believed that IL- $1 \alpha$ was only secreted passively from cells undergoing non-apoptotic cell death [25]; however, recent studies have demonstrated alternative control of IL-1 $\alpha$. WILlarT et al. [74] have shown that IL-1 $\alpha$ is secreted from airway epithelial cells following exposure to house dust mite, potentially affecting the inflammatory response in cystic fibrosis patients with reduced allergen clearance due to impaired mucociliary clearance. Recent studies have determined that the Nod-like receptor protein 3 (NLRP3) inflammasome regulates the active release of IL-1 $\alpha$ and IL-1 $\beta$ [75-77]. Stimulation via toll-like receptor signalling is sufficient to upregulate pro-IL-1 $\beta$ and to induce cell surface expression of IL- $1 \alpha$, but is insufficient for processing and extracellular release $[75,77]$. Activation of the NLRP3 inflammasome results in IL-1 $\beta$ processing and release and extracellular secretion of IL- $1 \alpha$ rather than cell surface expression [75-77]. FEтTELSchoss et al. [75] confirmed differential IL-1 $\alpha$ expression via biotinylation of surface IL- $1 \alpha$ and NLPR3 activation, and discovered IL- $1 \alpha$ secreted after inflammasome activation is not cleaved from the cell surface, but rather secreted from intracellular compartments. The pathways for IL- $1 \alpha$ surface expression and IL- $1 \alpha$ secretion are distinctly different, and dependent upon the activation of caspase- 1 and the presence of IL-1 $\beta$ for secretion to occur [75]. As IL- $1 \alpha$ does not contain a caspase- 1 cleavage site, dependency upon inflammasome activation and IL- $1 \beta$ can be explained by binding of IL- $1 \alpha$ and IL- $1 \beta$ for transport via IL- $1 \beta$ during transfer from the cytoplasm to extracellular space via caspase-1 [75]. Active secretion of IL- $1 \alpha$ during inflammasome activation is further compounded by necrotic airway cells during hypoxia, as ATP and mitochondria released from necrotic cells activate the NLRP3 inflammasome [28]. Hypoxia plays a role in inflammasome activation; mitochondrial ROS generated during hypoxia [78] have been demonstrated to activate the NLRP3 inflammasome, leading to pulmonary inflammation $[79,80]$. Inflammasome activation also results in significantly increased neutrophil influx into the airway, supporting a hypothesis for IL- $1 \alpha$ regulation in sterile inflammation driven by hypoxia $[28,81]$. The NLRP3 inflammasome is primed for activation by flagellin from bacteria such as Pseudomonas aeruginosa [82], explaining increased levels activated caspase-1 evident in cystic fibrosis mice [83], and potentially exacerbating NLRP3 activation in cystic fibrosis.

Neutrophilic inflammation following bacterial infection is mediated by toll-like receptor binding activating

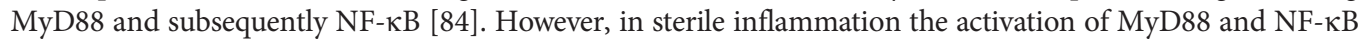
instead results from binding of IL-1 $\alpha$ to IL-1R [25] (figure 2). Fritzsching et al. [27] determined that IL-1 $\alpha$ released from necrotic airway epithelial cells and subsequent activation of IL-1RMyD88 signalling is an important pathway in the onset and perpetuation of neutrophilic inflammation in mice with cystic fibrosis-like lung disease. NF- $\mathrm{BB}$ is the key factor for neutrophil recruitment during inflammation [85], chiefly through release of the neutrophil chemoattractant IL-8 [86]. Hypoxia significantly increases IL-8 produced by alveolar macrophages [87], facilitating increased neutrophil influx to hypoxic areas already inundated by increased neutrophilia from inflammasome activation [81, 87]. In addition to increasing neutrophil influx, hypoxia also increases trans-epithelial migration of neutrophils [88] and subsequently the adherence of neutrophils to airway epithelial cells $[89,90]$, potentially exacerbating neutrophilic inflammation in the airway. Macrophages and neutrophils lacking HIF-1 $\alpha$ expression have reduced infiltration and activation in vivo, with HIF-1 $\alpha$ a basal regulator of energy metabolism in these cells [91]. Neutrophil survival is also influenced by HIF-1 $\alpha[92,93]$ and hypoxic neutrophils release significantly more neutrophil elastase [94], which was demonstrated to cause significant destruction of intestinal epithelium after acute alveolar hypoxia [95]. Finally, hypoxia impairs the killing of bacteria due to reduced oxidative burst capacity and inhibited glycolysis-induced ATP production $[91,95]$. During hypoxia, necrotic cells drive inflammation by passive and active IL- $1 \alpha$ release and subsequent IL-1R activation, resulting in neutrophil recruitment to the airway. These mechanisms may help explain the exaggerated neutrophilic inflammation present in early cystic fibrosis, and provide novel targets for anti-inflammatory therapies.

\section{Potential for therapy}

IL-1 receptor

IL-1R provides a novel target for attenuation of sterile inflammation in cystic fibrosis and potentially other chronic inflammatory lung diseases (figure 3). In rheumatoid arthritis, a disease characterised by IL- $1 \alpha$ driven inflammation, inhibition of IL-1R with IL-1R antagonist (IL-1Ra) is efficacious and commonplace [96]. However, there are limited data on the use of IL-1Ra to limit pulmonary inflammation in a disease setting. It has been demonstrated that IL-1Ra may reduce oxidative lung injury and neutrophil influx in rats administered IL-1Ra post-insult with IL-1 [97]. In a murine model of acute lung injury due to ventilation, IL-1Ra reduced airway neutrophil influx and expression of neutrophil chemoattractant and maintained 


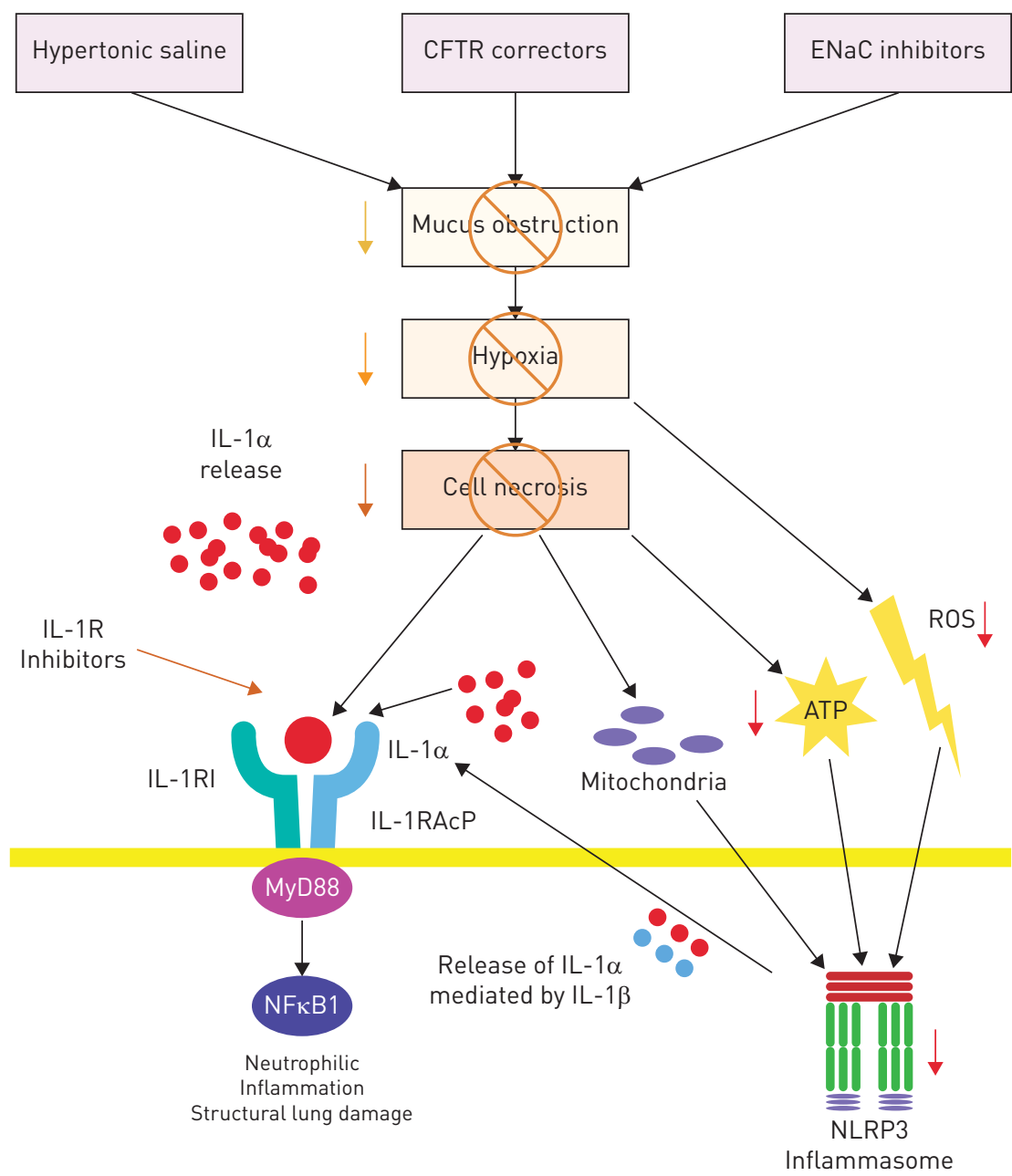

FIGURE 3 Potential therapies to alleviate hypoxia-driven inflammation. Potential therapies to alleviate hypoxia-driven inflammation under investigation target either mucous obstruction causing the hypoxia, or inhibition of IL-1R to disrupt the IL-1-nuclear factor $\kappa B(N F-\kappa B)$ inflammatory pathway. IL-1R inhibitors such as IL-1Ra and IL-1R antibodies bind to IL-1R, inhibiting stimulation of IL-1 $\alpha$ driven inflammation. Inhalation of hypertonic saline, cystic fibrosis transmembrane conductance regulator (CFTR) modulators or epithelial sodium channel $(\mathrm{ENaC})$ inhibitors improve airway surface hydration and mucociliary clearance in cystic fibrosis airways, alleviating mucus obstruction and resulting hypoxia. ROS: reactive oxygen species; NLRP3: Nod-like receptor protein 3 .

epithelial permeability [98]. Treatment of mice with IL-1Ra also prevented development of pulmonary fibrosis after inhalation of silica, predominantly affecting lung interstitial cells [99]. Neutrophils isolated from cystic fibrosis patients release significantly less IL-1Ra compared with neutrophils isolated from healthy individuals [100], which may suggest an imbalanced anti-inflammatory capacity in the cystic fibrosis airway. In a cystic fibrosis-like murine setting, pharmacological inhibition of IL-1R using IL-1Ra resulted in almost complete abrogation of airway neutrophilia and significantly reduced levels of keratinocyte chemoattractant, an IL-8 orthologue in mice [27]. Inhibition of airway neutrophilia was associated with a significant reduction in structural lung damage as determined from distal airspace enlargement characteristic of the murine model $[24,27]$. However, the moderate levels of reduction in airway mucus obstruction following IL-1Ra treatment were not sufficient to improve luminal $\mathrm{O}_{2}$ delivery to levels that results in reduced epithelial necrosis [27]. Even though inhibition of the IL-1R-MyD88 pathway resulted in reduced influx of neutrophils, recruitment and activation of macrophages remained intact in both the cystic fibrosis-like murine model and in mice with necrosis-induced inflammation $[25,27]$. Therefore, blocking IL-1R signalling via IL-1Ra may limit the damaging effects of neutrophils without compromising antibacterial host defence $[25,27]$.

\section{Mucus obstruction}

Other potential therapeutic approaches include improved oxygenation via prevention or reduction of airway mucus obstruction (figure 3). One common therapy currently recommended for improving mucus clearance in cystic fibrosis is the inhalation of aerosolised hypertonic saline. Although the exact mechanism of action 
of hypertonic saline is unknown, it is believed to draw water from epithelial cells and the serosal compartment via establishment of an osmotic gradient. Hypertonic saline is effective at transiently improving mucociliary clearance, demonstrated in both cystic fibrosis and non-cystic fibrosis disease [101, $102]$ and was shown to reduce mucus plugging and mortality effectively in mice with cystic fibrosis-like lung disease $[103,104]$. Pharmacological intervention with the classical ENaC blocker amiloride to inhibit $\mathrm{Na}^{+}$ absorption from cystic fibrosis airway surfaces has also been investigated as a therapy to reduce mucus obstruction, but resulting in no clinically significant improvements in cystic fibrosis patients with established lung disease $[105,106]$. This is likely due to low potency and short half-life of amiloride on airway surfaces [107]. However, a recent study utilising a cystic fibrosis-like murine model demonstrated that preventative treatment with amiloride starting in neonatal mice resulted in significantly reduced airway mucus obstruction, epithelial necrosis and airway inflammation, supporting that airway epithelial necrosis and associated inflammation can be reduced by therapeutic targeting of mucus plugging [104, 108]. Long-acting $\mathrm{ENaC}$ inhibitors with higher potency have been developed [109-111], but whether mucus obstruction and inflammation in established lung disease are abrogated by new therapeutics remains to be seen.

\section{CFTR modulation}

CFTR modulators, aimed at rescuing mutant CFTR function, such as ivacaftor and lumacaftor also have potential to alleviate airway mucus obstruction. Ivacaftor is a potentiator that improves $\mathrm{Cl}^{-}$transport of a series of mutant CFTR proteins that are expressed at the apical plasma membrane including gating mutations such as $\mathrm{G} 551 \mathrm{D}$, mutations causing reduced $\mathrm{Cl}^{-}$channel conductance such as $\mathrm{R} 117 \mathrm{H}$, and the common mutation F508del following correction of its trafficking defect [112-115]. Lumacaftor partially corrects the protein folding defects present in F508del-CFTR, improving the trafficking of F508del to the plasma membrane [116]. Both ivacaftor and lumacaftor work to restore CFTR function of responsive mutations $[112,116]$, resulting in improving mucociliary clearance and clinical outcomes $[117,118]$. Clinical trials involving combination therapies of ivacaftor/lumacaftor in patients with cystic fibrosis homozygous for F508del showed significant but modest improvements in lung function in cystic fibrosis patients older than 12 years of age, but it is currently too early to judge clinical significance of observed forced expiratory volume improvement [119]. Although safety and pharmacokinetics of ivacaftor in children under 6 years of age has been assessed [120], no controlled clinical trials have been performed, so use of both ivacaftor and lumacaftor is limited to after structural lung damage and airway mucus obstruction is already present. Clinical trials of ion transport modulators in young children with no detectable bacterial infection designed to determine if mucus obstruction and pulmonary inflammation is improved are warranted to provide insight regarding the roles of such interventions in preventing cystic fibrosis lung disease.

HIF-1 $\alpha$

Hypoxia-driven inflammation is characteristic of ischaemic and inflammatory diseases such as acute lung injury and colitis. Increased understanding of HIF-1 $\alpha$ regulation and downstream pathways is leading to new opportunities for pharmacological intervention and attenuation of hypoxia-driven inflammation. HIF- $1 \alpha$ is protective during hypoxia, important in maintaining epithelial barrier function [121]. This has been confirmed by a number of studies using a murine model of colitis [122, 123] and acts through increased expression of HIF-1-regulated barrier-protective genes, including, intestinal trefoil factor and CD73 [121]. The respiratory epithelium is important in respiratory hypoxia, with HIF-1 $\alpha$ stabilisation in alveolar epithelium demonstrated to be protective during acute lung injury [124]. This is achieved through increased glycolytic capacity, improved mitochondrial respiration and concomitant attenuation of lung inflammation [124]. Hypoxia-induced HIF-1 $\alpha$ stabilisation also affects wound healing; HIF-1 $\alpha$ and target gene vascular endothelial growth factor (VEGF) are detectable during wound re-epithelialisation [125]. Furthermore, VEGF is also upregulated during hypoxia [126] and has significant implications in epithelial wound repair under these conditions [127]. These studies suggest that pharmacological manipulation of HIF-1 $\alpha$ via PHD inhibition may be a therapeutic pathway to induce airway epithelial repair and potentially attenuate inflammation. Hydroxylase inhibitors such as iron chelators [128] are one therapeutic option that has shown protective effects in colitis $[122,123]$; however, they are largely non-specific for PHD inhibition. A more suitable approach may be through a recently identified novel class of PHD inhibitor [129], which acts by preferential binding directly to the PHD active sites. One of these novel inhibitors, TM6008, was observed to reduce cell death after hypoxic exposure [130]. Therefore, TM6008 may have potential to reduce the IL- $1 \alpha$ driven inflammation that is associated with necrotic cell death in hypoxic disease [27].

\section{Conclusion and future perspectives}

Mucus obstruction leading to localised respiratory hypoxia is characteristic in early cystic fibrosis, likely to contribute to early cystic fibrosis airway pathology. Transcriptional and physiological responses to hypoxia are altered in cystic fibrosis, with reduced HIF- $1 \alpha$ and NF- $\kappa$ B activation in cells lacking functional CFTR potentially exacerbating inflammation during hypoxia. Neutrophilic inflammation and neutrophil 
recruitment driven by IL- $1 \alpha$ released from necrotic cells resulting from hypoxia is exacerbated by NLRP3 inflammasome activated secretion of IL- $1 \alpha$. Once neutrophils are recruited to the airway, hypoxia significantly increases their survival, trans-epithelial migration and elastase release. Potential therapies to alleviate inflammation driven by IL-1R activation include: the use of IL-1R antagonists to inhibit activation by IL-1 $\alpha$; alleviation of mucus obstruction and resulting hypoxia via use of hypertonic saline to promote mucociliary transport; inhibition of ENaC-mediated $\mathrm{Na}^{+}$absorption with $\mathrm{ENaC}$ blockers and restoring CFTR channel function with CFTR modulators to improve airway surface hydration and mucus clearance and thus prevent mucus obstruction. Therapies to prevent or alleviate inflammation driven by hypoxia are in early stages of trials, or have previously shown no significant clinical effect. However, these studies used relatively crude clinical endpoints and none have yet been investigated as interventions to prevent the onset of structural lung disease $[105,106,110,119,130]$. Currently, the majority of targets for therapy are involved in the initial activation of the inflammatory pathway, but there is little research into activators further downstream in the pathway (figure 3). Future research could potentially target key genes in the $\mathrm{NF}-\kappa \mathrm{B}$ activation process, although such targets are less specific for hypoxia-driven inflammation and may have system wide effects including further impairment of host defence mechanisms in cystic fibrosis airways. Further study into the mechanisms of hypoxia-driven inflammation is required to identify feasibly actionable drug targets. These may include the replication of animal model studies using human-derived samples. Such studies would directly characterise human responses to hypoxia in the airway and elucidate specific mechanisms of cell death and IL- $1 \alpha$-driven inflammation. Answering these questions will result in deeper knowledge of the inflammatory environment within the respiratory system of patients with cystic fibrosis, with potential to identify targets for treatment to limit sterile inflammation in early childhood.

\section{Acknowledgements}

The authors thank Luke Garratt (Telethon Kids Institute, Perth, Australia) for help with manuscript preparation.

\section{References}

1 Welsh MJ, Smith AE. Molecular mechanisms of CFTR chloride channel dysfunction in cystic fibrosis. Cell 1993; 73: $1251-1254$

2 World Health Organization. The molecular genetic epidemiology of cystic fibrosis: Report of a joint meeting of WHO/ECFTN/ICF(M)A/ECFS, Genoa, Italy, 19 June 2002. 2004; 1-24. Available from www.who.int/genomics/ publications/en/HGN_WB_04.02_report.pdf Date last accessed: July 29, 2016. Date last updated: July 29, 2016.

3 Cystic Fibrosis Australia. Cystic Fibrosis In Australia 2014: 17th Annual Report from the Australian Cystic Fibrosis Data Registry. 2016; 17: 1-37. Available from www.cysticfibrosis.org.au/media/wysiwyg/CF-Australia/ medical-documents/CFA_DataRegistryReport_2014_Final.pdf Date last accessed: July 29, 2016. Date last updated: June 1,2016

4 Lai HJ, Cheng Y, Farrell PM. The survival advantage of patients with cystic fibrosis diagnosed through neonatal screening: evidence from the United States Cystic Fibrosis Foundation registry data. J Pediatr 2005; 147: 3 Suppl, S57-S63.

5 Lai HJ, Shoff SM, Farrell PM, et al. Recovery of birth weight $\mathrm{z}$ score within 2 years of diagnosis is positively associated with pulmonary status at 6 years of age in children with cystic fibrosis. Pediatrics 2009; 123: 714-722.

6 Merelle ME, Schouten JP, Gerritsen J, et al. Influence of neonatal screening and centralized treatment on long-term clinical outcome and survival of CF patients. Eur Respir J 2001; 18: 306-315.

7 Farrell PM, Kosorok MR, Rock MJ, et al. Early diagnosis of cystic fibrosis through neonatal screening prevents severe malnutrition and improves long-term growth. Wisconsin Cystic Fibrosis Neonatal Screening Study Group. Pediatrics 2001; 107: 1-13.

$8 \quad$ Mall MA, Hartl D. CFTR: cystic fibrosis and beyond. Eur Respir J, 2014; 44: 1042-1054.

9 Quinton PM. Chloride impermeability in cystic fibrosis. Nature 1983; 301: 421-422.

10 Boucher RC, Stutts MJ, Knowles MR, et al. $\mathrm{Na}^{+}$transport in cystic fibrosis respiratory epithelia. Abnormal basal rate and response to adenylate cyclase activation. J Clin Invest 1986; 78: 1245-1252.

11 Mall M, Grubb BR, Harkema JR, et al. Increased airway epithelial $\mathrm{Na}^{+}$absorption produces cystic fibrosis-like lung disease in mice. Nat Med 2004; 10: 487-493.

12 Stutts MJ, Canessa CM, Olsen JC, et al. CFTR as a cAMP-dependent regulator of sodium channels. Science 1995; 269: 847-850.

13 Mall M, Bleich $\mathrm{M}$, Greger $\mathrm{R}$, et al. The amiloride-inhibitable $\mathrm{Na}^{+}$conductance is reduced by the cystic fibrosis transmembrane conductance regulator in normal but not in cystic fibrosis airways. J Clin Invest 1998; 102: 15-21.

14 Mall M, Hipper A, Greger R, et al. Wild type but not deltaF508 CFTR inhibits Na+ conductance when coexpressed in Xenopus oocytes. FEBS Lett 1996; 381: 47-52.

15 Matsui $\mathrm{H}$, Grubb BR, Tarran R, et al. Evidence for periciliary liquid layer depletion, not abnormal ion composition, in the pathogenesis of cystic fibrosis airways disease. Cell 1998; 95: 1005-1015.

16 Henderson AG, Ehre C, Button B, et al. Cystic fibrosis airway secretions exhibit mucin hyperconcentration and increased osmotic pressure. J Clin Invest 2014; 124: 3047-3060.

17 Worlitzsch D, Tarran R, Ulrich M, et al. Effects of reduced mucus oxygen concentration in airway Pseudomonas infections of cystic fibrosis patients. J Clin Invest 2002; 109: 317-325.

18 Stutts MJ, Knowles MR, Gatzy JT, et al. Oxygen consumption and ouabain binding sites in cystic fibrosis nasal epithelium. Pediatr Res 1986; 20: 1316-1320.

19 Gehrig S, Duerr J, Weitnauer M, et al. Lack of neutrophil elastase reduces inflammation, mucus hypersecretion, and emphysema, but not mucus obstruction, in mice with cystic fibrosis-like lung disease. Am J Respir Crit Care Med 2014; 189: 1082-1092. 
Stick SM, Brennan S, Murray C, et al. Bronchiectasis in infants and preschool children diagnosed with cystic fibrosis after newborn screening. J Pediatr 2009; 155: 623-628.

Pereira LC, Moreira EA, Bennemann GD, et al. Influence of inflammatory response, infection, and pulmonary function in cystic fibrosis. Life Sci 2014; 109: 30-36.

Sly PD, Gangell CL, Chen L, et al. Risk factors for bronchiectasis in children with cystic fibrosis. N Engl J Med 2013; 368: 1963-1970.

Wielputz MO, Puderbach M, Kopp-Schneider A, et al. Magnetic resonance imaging detects changes in structure and perfusion, and response to therapy in early cystic fibrosis lung disease. Am J Respir Crit Care Med 2014; 189: 956-965.

Mall MA, Harkema JR, Trojanek JB, et al. Development of chronic bronchitis and emphysema in beta-epithelial $\mathrm{Na}+$ channel-overexpressing mice. Am J Respir Crit Care Med 2008; 177: 730-742.

Chen CJ, Kono H, Golenbock D, et al. Identification of a key pathway required for the sterile inflammatory response triggered by dying cells. Nat Med 2007; 13: 851-856.

Eigenbrod T, Park JH, Harder J, et al. Cutting edge: critical role for mesothelial cells in necrosis-induced inflammation through the recognition of IL-1 alpha released from dying cells. J Immunol 2008; 181: 8194-8198.

Fritzsching B, Zhou-Suckow Z, Trojanek JB, et al. Hypoxic epithelial necrosis triggers neutrophilic inflammation via IL-1 receptor signaling in cystic fibrosis lung disease. Am J Respir Crit Care Med 2015; 191: 902-913.

Iyer SS, Pulskens WP, Sadler JJ, et al. Necrotic cells trigger a sterile inflammatory response through the Nlrp3 inflammasome. Proc Natl Acad Sci USA 2009; 106: 20388-20393.

Luheshi NM, Kovacs KJ, Lopez-Castejon G, et al. Interleukin-lalpha expression precedes IL-1beta after ischemic brain injury and is localised to areas of focal neuronal loss and penumbral tissues. J Neuroinflammation 2011; 8: 186. Fraser KL, Tullis DE, Sasson Z, et al. Pulmonary hypertension and cardiac function in adult cystic fibrosis: role of hypoxemia. Chest 1999; 115: 1321-1328.

Williamson KS, Richards LA, Perez-Osorio AC, et al. Heterogeneity in Pseudomonas aeruginosa biofilms includes expression of ribosome hibernation factors in the antibiotic-tolerant subpopulation and hypoxia-induced stress response in the metabolically active population. J Bacteriol 2012; 194: 2062-2073.

Sly PD, Brennan S, Gangell C, et al. Lung disease at diagnosis in infants with cystic fibrosis detected by newborn screening. Am J Respir Crit Care Med 2009; 180: 146-152.

Brooks AJ, Eastwood J, Beckingham IJ, et al. Liver tissue partial pressure of oxygen and carbon dioxide during partial hepatectomy. Br J Anaesth 2004; 92: 735-737.

Bylund-Fellenius AC, Walker PM, Elander A, et al. Energy metabolism in relation to oxygen partial pressure in human skeletal muscle during exercise. Biochem J 1981; 200: 247-255.

Dings J, Meixensberger J, Jager A, et al. Clinical experience with 118 brain tissue oxygen partial pressure catheter probes. Neurosurgery 1998; 43: 1082-1095.

Kubo K, Hanaoka M, Hayano T, et al. Inflammatory cytokines in BAL fluid and pulmonary hemodynamics in high-altitude pulmonary edema. Respir Physiol 1998; 111: 301-310.

Villa MP, Pagani J, Lucidi V, et al. Nocturnal oximetry in infants with cystic fibrosis. Arch Dis Child 2001; 84: 50-54.

Post JM, Hume JR, Archer SL, et al. Direct role for potassium channel inhibition in hypoxic pulmonary vasoconstriction. Am J Physiol 1992; 262: C882-C890.

Yuan XJ, Tod ML, Rubin LJ, et al. Contrasting effects of hypoxia on tension in rat pulmonary and mesenteric arteries. Am J Physiol 1990; 259: H281-H289.

Wilkinson M, Langhorne CA, Heath D, et al. A pathophysiological study of 10 cases of hypoxic cor pulmonale. Q J Med 1988; 66: 65-85.

Wang GL, Jiang BH, Rue EA, et al. Hypoxia-inducible factor 1 is a basic-helix-loop-helix-PAS heterodimer regulated by cellular O2 tension. Proc Natl Acad Sci USA 1995; 92: 5510-5514.

Huang LE, Gu J, Schau M, et al. Regulation of hypoxia-inducible factor $1 \alpha$ is mediated by an $\mathrm{O}_{2}$-dependent degradation domain via the ubiquitin-proteasome pathway. Proc Natl Acad Sci USA 1998; 95: 7987-7992.

Jaakkola P, Mole DR, Tian YM, et al. Targeting of HIF-alpha to the von Hippel-Lindau ubiquitylation complex by O2-regulated prolyl hydroxylation. Science 2001; 292: 468-472.

Maxwell PH, Wiesener MS, Chang GW, et al. The tumour suppressor protein VHL targets hypoxia-inducible factors for oxygen-dependent proteolysis. Nature 1999; 399: 271-275.

Legendre C, Mooij MJ, Adams C, et al. Impaired expression of hypoxia-inducible factor-1alpha in cystic fibrosis airway epithelial cells - a role for HIF-1 in the pathophysiology of CF?J Cyst Fibros 2011; 10: 286-290.

Tajima M, Kurashima Y, Sugiyama K, et al. The redox state of glutathione regulates the hypoxic induction of HIF-1. Eur J Pharmacol 2009; 606: 45-49. 2003; 22: 1981-1989. Gould NS, Gauthier S, Kariya CT, et al. Hypertonic saline increases lung epithelial lining fluid glutathione and thiocyanate: two protective CFTR-dependent thiols against oxidative injury. Respir Res 2010; 11: 119.

Duranton C, Rubera I, Cougnon M, et al. CFTR is involved in the fine tuning of intracellular redox status: physiological implications in cystic fibrosis. Am J Pathol 2012; 181: 1367-1377.

Culver C, Sundqvist A, Mudie S, et al. Mechanism of hypoxia-induced NF-kappaB. Mol Cell Biol 2010; 30: 4901-4921.

Koong AC, Chen EY, Giaccia AJ. Hypoxia causes the activation of nuclear factor kappa B through the phosphorylation of I kappa B alpha on tyrosine residues. Cancer Res 1994; 54: 1425-1430.

Cummins EP, Berra E, Comerford KM, et al. Prolyl hydroxylase-1 negatively regulates IkappaB kinase-beta, giving insight into hypoxia-induced NFkappaB activity. Proc Natl Acad Sci USA 2006; 103: 18154-18159.

DiDonato JA, Hayakawa M, Rothwarf DM, et al. A cytokine-responsive I kappa B kinase that activates the transcription factor NF-kappa B. Nature 1997; 388: 548-554.

Aley PK, Porter KE, Boyle JP, et al. Hypoxic modulation of $\mathrm{Ca}^{2+}$ signaling in human venous endothelial cells. Multiple roles for reactive oxygen species. J Biol Chem 2005; 280: 13349-13354.

Rius J, Guma M, Schachtrup C, et al. NF-kappaB links innate immunity to the hypoxic response through transcriptional regulation of HIF-1alpha. Nature 2008; 453: 807-811. 

Pseudomonas aeruginosa binding, internalization, and initiation of inflammation. Invest Ophthalmol Vis Sci 2004; 45: 4066-4074.

57 Hirche TO, Benabid R, Deslee G, et al. Neutrophil elastase mediates innate host protection against Pseudomonas aeruginosa. J Immunol 2008; 181: 4945-4954.

58 Hartl D, Latzin P, Hordijk P, et al. Cleavage of CXCR1 on neutrophils disables bacterial killing in cystic fibrosis lung disease. Nat Med 2007; 13: 1423-1430.

59 Caldwell RA, Boucher RC, Stutts MJ. Neutrophil elastase activates near-silent epithelial $\mathrm{Na}^{+}$channels and increases airway epithelial Na+ transport. Am J Physiol Lung Cell Mol Physiol 2005; 288: L813-L819.

60 Le Gars M, Descamps D, Roussel D, et al. Neutrophil elastase degrades cystic fibrosis transmembrane conductance regulator via calpains and disables channel function in vitro and in vivo. Am J Respir Crit Care Med 2013; 187: 170-179.

61 Armstrong DS, Hook SM, Jamsen KM, et al. Lower airway inflammation in infants with cystic fibrosis detected by newborn screening. Pediatr Pulmonol 2005; 40: 500-510.

62 Mall MA, Graeber SY, Stahl M, et al. Early cystic fibrosis lung disease: Role of airway surface dehydration and lessons from preventive rehydration therapies in mice. Int J Biochem Cell Biol 2014; 52: 174-179.

63 Livraghi-Butrico A, Kelly EJ, Klem ER, et al. Mucus clearance, MyD88-dependent and MyD88-independent immunity modulate lung susceptibility to spontaneous bacterial infection and inflammation. Mucosal Immunol 2012; 5: 397-408.

64 Lukens JR, Gross JM, Kanneganti TD. IL-1 family cytokines trigger sterile inflammatory disease. Front Immunol 2012; 3: 315.

65 Haq M, Norman J, Saba SR, et al. Role of IL-1 in renal ischemic reperfusion injury. J Am Soc Nephrol 1998; 9: 614-619.

66 Galea J, Armstrong J, Gadsdon P, et al. Interleukin-1 beta in coronary arteries of patients with ischemic heart disease. Arterioscler Thromb Vasc Biol 1996; 16: 1000-1006.

67 Suzuki K, Murtuza B, Smolenski RT, et al. Overexpression of interleukin-1 receptor antagonist provides cardioprotection against ischemia-reperfusion injury associated with reduction in apoptosis. Circulation 2001; 104: 12 Suppl 1, I308-I313.

68 Cohen I, Rider P, Carmi Y, et al. Differential release of chromatin-bound IL-1alpha discriminates between necrotic and apoptotic cell death by the ability to induce sterile inflammation. Proc Natl Acad Sci USA 2010; 107: 2574-2579. Gross O, Yazdi AS, Thomas CI, et al. Inflammasome activators induce interleukin-1alpha secretion via distinct pathways with differential requirement for the protease function of caspase-1. Immunity 2012; 36: 388-400.

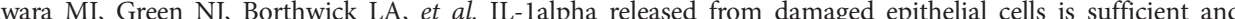
essential to trigger inflammatory responses in human lung fibroblasts. Mucosal Immunol 2014; 7: 684-693.

71 Kobayashi Y, Yamamoto K, Saido T, et al. Identification of calcium-activated neutral protease as a processing enzyme of human interleukin 1 alpha. Proc Natl Acad Sci USA 1990; 87: 5548-5552.

72 Zheng Y, Humphry M, Maguire JJ, et al. Intracellular interleukin-1 receptor 2 binding prevents cleavage and activity of interleukin-1alpha, controlling necrosis-induced sterile inflammation. Immunity 2013; 38: $285-295$.

73 Coulter KR, Wewers MD, Lowe MP, et al. Extracellular regulation of interleukin (IL)-1beta through lung epithelial cells and defective IL-1 type II receptor expression. Am J Respir Cell Mol Biol 1999; 20: 964-975.

74 Willart MA, Deswarte K, Pouliot P, et al. Interleukin-1alpha controls allergic sensitization to inhaled house dust mite via the epithelial release of GM-CSF and IL-33. J Exp Med 2012; 209: 1505-1517.

75 Fettelschoss A, Kistowska M, LeibundGut-Landmann S, et al. Inflammasome activation and IL-1beta target IL-1alpha for secretion as opposed to surface expression. Proc Natl Acad Sci USA 2011; 108: 18055-18060.

76 Yazdi AS, Guarda G, Riteau N, et al. Nanoparticles activate the NLR pyrin domain containing 3 (Nlrp3) inflammasome and cause pulmonary inflammation through release of IL-1alpha and IL-1beta. Proc Natl Acad Sci U S A 2010; 107: 19449-19454.

77 Cullen SP, Kearney CJ, Clancy DM, et al. Diverse Activators of the NLRP3 Inflammasome Promote IL-1beta Secretion by Triggering Necrosis. Cell Rep 2015; 11: 1535-1548.

78 Chandel NS, McClintock DS, Feliciano CE, et al. Reactive oxygen species generated at mitochondrial complex III stabilize hypoxia-inducible factor-1alpha during hypoxia: a mechanism of $\mathrm{O}_{2}$ sensing. J Biol Chem 2000; 275: $25130-25138$

79 Kim SR, Kim DI, Kim SH, et al. NLRP3 inflammasome activation by mitochondrial ROS in bronchial epithelial cells is required for allergic inflammation. Cell Death Dis 2014; 5: e1498.

80 Heid ME, Keyel PA, Kamga C, et al. Mitochondrial reactive oxygen species induces NLRP3-dependent lysosomal damage and inflammasome activation. J Immunol 2013; 191: 5230-5238.

81 Cero FT, Larsen KO, Christensen G, et al. Hypoxia induces inflammasome activation and influx of neutrophils and T-cells in the lungs. Eur Respir J 2014; 42: Suppl 57; P652.

82 Rimessi A, Bezzerri V, Patergnani S, et al. Mitochondrial $\mathrm{Ca}^{2+}$-dependent NLRP3 activation exacerbates the Pseudomonas aeruginosa-driven inflammatory response in cystic fibrosis. Nat Commun 2015; 6: 6201.

83 Grassme H, Carpinteiro A, Edwards MJ, et al. Regulation of the inflammasome by ceramide in cystic fibrosis lungs. Cell Physiol Biochem 2014; 34: 45-55.

84 Skerrett SJ, Liggitt HD, Hajjar AM, et al. Cutting edge: myeloid differentiation factor 88 is essential for pulmonary host defense against Pseudomonas aeruginosa but not Staphylococcus aureus. I Immunol 2004; 172: 3377-3381.

85 Sadikot RT, Han W, Everhart MB, et al. Selective IкB kinase expression in airway epithelium generates neutrophilic lung inflammation. J Immunol 2003; 170: 1091-1098.

86 Huber AR, Kunkel SL, Todd RF III, et al. Regulation of transendothelial neutrophil migration by endogenous interleukin-8. Science 1991; 254: 99-102.

87 Hirani N, Antonicelli F, Strieter RM, et al. The regulation of interleukin- 8 by hypoxia in human macrophages: -a potential role in the pathogenesis of the acute respiratory distress syndrome (ARDS). Mol Med 2001; 7: 685-697.

88 Colgan SP, Dzus AL, Parkos CA. Epithelial exposure to hypoxia modulates neutrophil transepithelial migration. J Exp Med 1996; 184: 1003-1015.

89 Beck-Schimmer B, Schimmer RC, Madjdpour C, et al. Hypoxia mediates increased neutrophil and macrophage adhesiveness to alveolar epithelial cells. Am J Respir Cell Mol Biol 2001; 25: 780-787. 

induction of beta2 integrin gene expression. Proc Natl Acad Sci USA 2004; 101: 10440-10445.

91 Cramer T, Yamanishi Y, Clausen BE, et al. HIF-1 $\alpha$ Is Essential for Myeloid Cell-Mediated Inflammation. Cell 2003; 112: 645-657.

92 Walmsley SR, Print C, Farahi N, et al. Hypoxia-induced neutrophil survival is mediated by HIF-1alphadependent NF-kappaB activity. J Exp Med 2005; 201: 105-115.

93 Elks PM, van Eeden FJ, Dixon G, et al. Activation of hypoxia-inducible factor-1alpha (Hif-1alpha) delays inflammation resolution by reducing neutrophil apoptosis and reverse migration in a zebrafish inflammation model. Blood 2011; 118: 712-722.

94 McGovern NN, Cowburn AS, Porter L, et al. Hypoxia selectively inhibits respiratory burst activity and killing of Staphylococcus aureus in human neutrophils. J Immunol 2011; 186: 453-463.

95 Nakamura N, Morisaki H, Suzuki T, et al. Inhibition of neutrophil elastase attenuates gut mucosal injury evoked by acute alveolar hypoxia in rabbits. Shock 2007; 28: 101-105.

96 Bresnihan B, Alvaro-Gracia JM, Cobby M, et al. Treatment of rheumatoid arthritis with recombinant human interleukin-1 receptor antagonist. Arthritis Rheum 1998; 41: 2196-2204.

97 Leff JA, Bodman ME, Cho OJ, et al. Post-insult treatment with interleukin-1 receptor antagonist decreases oxidative lung injury in rats given intratracheal interleukin-1. Am J Respir Crit Care Med 1994; 150: 109-112.

98 Frank JA, Pittet JF, Wray C, et al. Protection from experimental ventilator-induced acute lung injury by IL-1 receptor blockade. Thorax 2008; 63: 147-153.

99 Piguet PF, Vesin C, Grau GE, et al. Interleukin 1 receptor antagonist (IL-1ra) prevents or cures pulmonary fibrosis elicited in mice by bleomycin or silica. Cytokine 1993; 5: 57-61.

100 Corvol H, Fitting C, Chadelat K, et al. Distinct cytokine production by lung and blood neutrophils from children with cystic fibrosis. Am J Physiol Lung Cell Mol Physiol 2003; 284: L997-1003.

101 Robinson M, Hemming AL, Regnis JA, et al. Effect of increasing doses of hypertonic saline on mucociliary clearance in patients with cystic fibrosis. Thorax 1997; 52: 900-903.

102 Sloane PA, Shastry S, Wilhelm A, et al. A pharmacologic approach to acquired cystic fibrosis transmembrane conductance regulator dysfunction in smoking related lung disease. PLoS ONE 2012; 7: e39809.

103 Graeber SY, Zhou-Suckow Z, Schatterny J, et al. Hypertonic saline is effective in the prevention and treatment of mucus obstruction, but not airway inflammation, in mice with chronic obstructive lung disease. Am J Respir Cell Mol Biol 2013; 49: 410-417.

104 Mall MA. Unplugging mucus in cystic fibrosis and chronic obstructive pulmonary disease. Ann Am Thorac Soc 2016; 13: Suppl. 2, S177-S185.

105 Graham A, Hasani A, Alton EWFW, et al. No added benefit from nebulized amiloride in patients with cystic-fibrosis. Eur Respir J 1993; 6: 1243-1248.

106 Pons G, Marchand MC, d'Athis P, et al. French multicenter randomized double-blind placebo-controlled trial on nebulized amiloride in cystic fibrosis patients. The Amiloride-AFLM Collaborative Study Group. Pediatr Pulmonol 2000; 30: 25-31.

107 Noone PG, Regnis JA, Liu X, et al. Airway deposition and clearance and systemic pharmacokinetics of amiloride following aerosolization with an ultrasonic nebulizer to normal airways. Chest 1997; 112: 1283-1290.

108 Zhou Z, Treis D, Schubert SC, et al. Preventive but not late amiloride therapy reduces morbidity and mortality of lung disease in betaENaC-overexpressing mice. Am J Respir Crit Care Med 2008; 178: 1245-1256.

109 Hirsh AJ, Molino BF, Zhang J, et al. Design, synthesis, and structure-activity relationships of novel 2-substituted pyrazinoylguanidine epithelial sodium channel blockers: drugs for cystic fibrosis and chronic bronchitis. $J$ Med Chem 2006; 49: 4098-4115.

110 Hobbs CA, Blanchard MG, Alijevic O, et al. Identification of the SPLUNC1 ENaC-inhibitory domain yields novel strategies to treat sodium hyperabsorption in cystic fibrosis airway epithelial cultures. Am J Physiol Lung Cell Mol Physiol 2013; 305: L990-L1001.

111 Hunt T, Atherton-Watson HC, Axford J, et al. Discovery of a novel chemotype of potent human ENaC blockers using a bioisostere approach. Part 1: quaternary amines. Bioorg Med Chem Lett 2012; 22: 929-932.

112 Jih KY, Hwang TC. Vx-770 potentiates CFTR function by promoting decoupling between the gating cycle and ATP hydrolysis cycle. Proc Natl Acad Sci USA 2013; 110: 4404-4409.

$113 \mathrm{Yu} \mathrm{H}$, Burton B, Huang C-J, et al. Ivacaftor potentiation of multiple CFTR channels with gating mutations. J Cyst Fibros 2012; 11: 237-245.

114 Boyle MP, Bell SC, Konstan MW, et al. A CFTR corrector (lumacaftor) and a CFTR potentiator (ivacaftor) for treatment of patients with cystic fibrosis who have a phe508del CFTR mutation: a phase 2 randomised controlled trial. Lancet Respir Med 2014; 2: 527-538.

115 Ronan NJ, Fleming C, O'Callaghan G, et al. The role of ivacaftor in severe cystic fibrosis in a patient with the R117H mutation. Chest 2015; 148: e72-e75.

116 Ren HY, Grove DE, De La Rosa O, et al. VX-809 corrects folding defects in cystic fibrosis transmembrane conductance regulator protein through action on membrane-spanning domain 1. Mol Biol Cell 2013; 24: 3016-3024.

117 Rowe SM, Heltshe SL, Gonska T, et al. Clinical mechanism of the cystic fibrosis transmembrane conductance regulator potentiator ivacaftor in G551D-mediated cystic fibrosis. Am J Respir Crit Care Med 2014; 190: 175-184.

118 Clancy JP, Rowe SM, Accurso FJ, et al. Results of a phase IIa study of VX-809, an investigational CFTR corrector compound, in subjects with cystic fibrosis homozygous for the F508del-CFTR mutation. Thorax 2012; 67: $12-18$.

119 Wainwright CE, Elborn JS, Ramsey BW, et al. Lumacaftor-ivacaftor in patients with cystic fibrosis homozygous for Phe508del CFTR. N Engl J Med 2015; 373: 220-231.

120 Davies JC, Cunningham S, Harris WT, et al. Safety, pharmacokinetics, and pharmacodynamics of ivacaftor in patients aged 2-5 years with cystic fibrosis and a CFTR gating mutation (KIWI): an open-label, single-arm study. Lancet Respir Med 2016; 4: 107-115.

121 Karhausen J, Furuta GT, Tomaszewski JE, et al. Epithelial hypoxia-inducible factor-1 is protective in murine experimental colitis. J Clin Invest 2004; 114: 1098-1106.

122 Robinson A, Keely S, Karhausen J, et al. Mucosal protection by hypoxia-inducible factor prolyl hydroxylase inhibition. Gastroenterology 2008; 134: 145-155. 
123 Cummins EP, Seeballuck F, Keely SJ, et al. The hydroxylase inhibitor dimethyloxalylglycine is protective in a murine model of colitis. Gastroenterology 2008; 134: 156-165.

124 Eckle T, Brodsky K, Bonney M, et al. HIF1A reduces acute lung injury by optimizing carbohydrate metabolism in the alveolar epithelium. PLoS Biol 2013; 11: e1001665.

125 Elson DA, Ryan HE, Snow JW, et al. Coordinate up-regulation of hypoxia inducible factor (HIF)-1alpha and HIF-1 target genes during multi-stage epidermal carcinogenesis and wound healing. Cancer Res 2000; 60: 6189-6195.

126 Pham I, Uchida T, Planes C, et al. Hypoxia upregulates VEGF expression in alveolar epithelial cells in vitro and in vivo. Am J Physiol Lung Cell Mol Physiol 2002; 283: L1133-L1142.

127 Roberts JR, Perkins GD, Fujisawa T, et al. Vascular endothelial growth factor promotes physical wound repair and is anti-apoptotic in primary distal lung epithelial and A549 cells. Crit Care Med 2007; 35: 2164-2170.

128 Wang GL, Semenza GL. Desferrioxamine induces erythropoietin gene expression and hypoxia-inducible factor 1 DNA-binding activity: implications for models of hypoxia signal transduction. Blood 1993; 82: 3610-3615.

129 Nangaku M, Izuhara Y, Takizawa S, et al. A novel class of prolyl hydroxylase inhibitors induces angiogenesis and exerts organ protection against ischemia. Arterioscler Thromb Vasc Biol 2007; 27: 2548-2554.

130 Kontani S, Nagata E, Uesugi T, et al. A novel prolyl hydroxylase inhibitor protects against cell death after hypoxia. Neurochem Res 2013; 38: 2588-2594. 